\title{
Article \\ Disturbance of Vancomycin Infusion Flow during Multidrug Infusion: Influence on Endothelial Cell Toxicity
}

\author{
Maryline Drouet ${ }^{1}$, Elodie Cuvelier ${ }^{1,2, * \mathbb{D}}$, Feng Chai ${ }^{3}$, Stéphanie Genay ${ }^{1,2} \mathbb{D}$, Pascal Odou ${ }^{1,2}$ \\ and Bertrand Décaudin ${ }^{1,2}$ (D)
}

1 CHU Lille, ULR 7365-GRITA—Groupe de Recherche sur les Formes Injectables et les Technologies Associées, University Lille, F-59000 Lille, France; maryline.drouet@gmail.com (M.D.); stephanie.genay@univ-lille.fr (S.G.); pascal.odou@univ-lille.fr (P.O.); bertrand.decaudin@univ-lille.fr (B.D.)

2 CHU Lille, Institut de Pharmacie, F-59000 Lille, France

3 Institut National de la Santé et de la Recherche Médicale (INSERM) U1008, University of Lille, UFR3S, 1 Place de Verdun, F-59000 Lille, France; feng.hildebrand@univ-lille.fr

* Correspondence: elodie.cuvelier@univ-lille.fr

Citation: Drouet, M.; Cuvelier, E.; Chai, F.; Genay, S.; Odou, P.; Décaudin, B. Disturbance of Vancomycin Infusion Flow during Multidrug Infusion: Influence on Endothelial Cell Toxicity. Antibiotics 2022, 11, 16. https://doi.org/ 10.3390/antibiotics 11010016

Academic Editor: Carlos M. Franco

Received: 11 November 2021

Accepted: 21 December 2021

Published: 24 December 2021

Publisher's Note: MDPI stays neutral with regard to jurisdictional claims in published maps and institutional affiliations.

Copyright: (C) 2021 by the authors. Licensee MDPI, Basel, Switzerland. This article is an open access article distributed under the terms and conditions of the Creative Commons Attribution (CC BY) license (https:// creativecommons.org/licenses/by/ $4.0 /)$.

\begin{abstract}
Background: Phlebitis is a common side effect of vancomycin peripheral intravenous (PIV) infusion. As only one PIV catheter is frequently used to deliver several drugs to hospitalized patients through the same Y-site, perturbation of the infusion flow by hydration or other IV medication may influence vancomycin exposure to endothelial cells and modulate toxicity. Methods: We assessed the toxicity of variations in vancomycin concentration induced by drug mass flow variations in human umbilical vein endothelial cells (HUVECs), simulating a $24 \mathrm{~h}$ multi-infusion therapy on the same line. Results were expressed as the percentage of viable cells compared with a $100 \%$ control, and the Kruskal-Wallis test was used to assess the toxicity of vancomycin. Results: Our results showed that variations in vancomycin concentration did not significantly influence local toxicity compared to a fixed concentration of vancomycin. Nevertheless, the loss of cell viability induced by mechanical trauma mimicking multidrug infusion could increase the risk of phlebitis. Conclusion: To ensure that vancomycin-induced phlebitis must have other causes than variation in drug mass flow, further in vitro experiments should be performed to limit mechanical stress to frequent culture medium change.
\end{abstract}

Keywords: vancomycin; phlebitis; human umbilical vein endothelial cells; infusions; intravenous; simulation; in vitro techniques; toxicity tests

\section{Introduction}

Drug-associated phlebitis may be influenced by chemical and/or physical mechanisms. In particular, phlebitis is an adverse effect of vancomycin, as described in the literature [1,2], occurring at a frequency of $1-10 \%$ according to the product summary [3]. An Iranian study showed that the frequency of occurrence of phlebitis in children treated with vancomycin was dependent on the infusion modality (45.90 and 89.10\%) [4]. This treatment causes concentration-dependent phlebitis: it appears to be less frequent when administered at a concentration below $5 \mathrm{mg} / \mathrm{mL}$ and better tolerated at a final concentration of $2 \mathrm{mg} / \mathrm{mL}[4,5]$. In previous studies, we analyzed factors influencing vancomycin (VAN)associated phlebitis in peripheral intravenous (PIV) infusion. We showed that vancomycin endothelial toxicity depended on concentration and infusion duration [6] and that vancomycin in combination with other antibiotics increased endothelial toxicity, enabling us to recommend using a separate line to infuse vancomycin via a PIV access [7]. However, in surgical and intensive care units, multiple simultaneous infusion of several drugs with one catheter (multi-infusion) could lead to dosing errors and highs and lows in medication levels [8,9]. Moreover, our studies showed unexpected flow variations in PIV infusion during multi-infusion therapy through a single intravenous (IV) access, inducing variations in drug mass flow $[10,11]$. Disturbance to the infusion flow by hydration or other IV 
medication could influence vancomycin exposure to endothelial cells and modulate local toxicity. Notably, an inadvertent bolus can appear when carrier flow is restored abruptly in the reservoir with a dead volume [9]. The aim of this study was to assess the toxicity of variations in vancomycin concentration under in vitro conditions simulating multi-infusion on the same line to determine whether vancomycin flow rate variations increase local endothelial toxicity.

\section{Results}

Our result showed that vancomycin maintained at a fixed concentration for $24 \mathrm{~h}$ in a culture medium of human umbilical vein endothelial cells (HUVECs) caused a concentration-dependent loss of cell viability of about $40 \%$ for $4 \mathrm{mg} / \mathrm{mL}$, which was consistent with previous results [6]. A further loss of viability (20.0 $\pm 5.8 \%)$ was observed for vancomycin at variable concentrations compared to vancomycin at a fixed concentration without removing the culture medium (Figure 1).
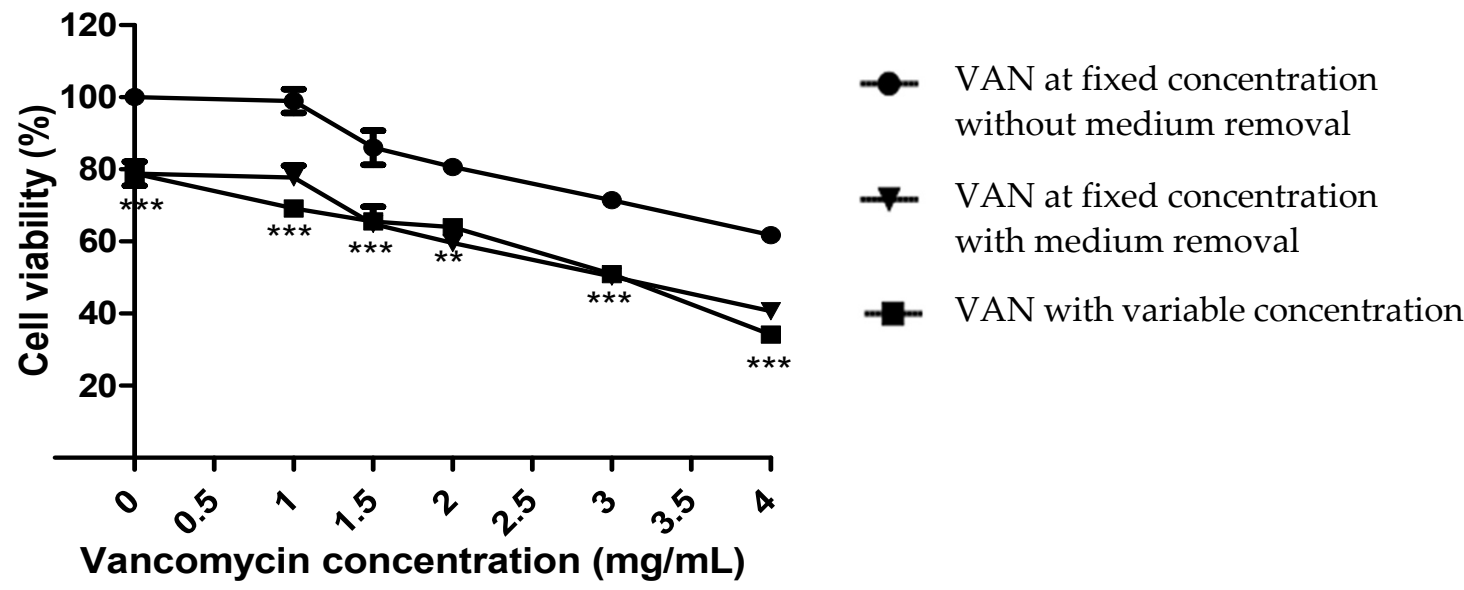

Figure 1. Cell viability of HUVECs after $24 \mathrm{~h}$ contact with vancomycin. Vancomycin (VAN) concentration ranged from $1 \mathrm{mg} / \mathrm{mL}$ to $4 \mathrm{mg} / \mathrm{mL}$. ${ }^{* *} p<0.01$, ${ }^{* * *} p<0.001$, for the comparison between VAN at a fixed concentration without medium removal and VAN with variable concentration. $n=3$, error bars represent the standard error of the mean.

However, no significant difference was observed regarding the rate of cell death between condition 2 (fixed concentration of vancomycin with medium removal) and condition 3 (variable concentration of vancomycin) (Figure 1), signifying that the excess mortality observed was induced by cellular stress due to solution removal and the addition of fresh solution (Figure 1).

\section{Discussion}

The availability of HUVECs to test drug solutions for intravenous compatibility is a valuable alternative to animal models, as has been demonstrated by several studies which have analyzed antibiotic compatibility and the inflammatory process on HUVECs [12,13]. In this study, we wanted to mimic a $10 \mathrm{~h}$ continuous infusion of vancomycin because continuous infusion of vancomycin is preferred in Europe. The cytoxicity analysis after several hours of incubation allows us to quantify the toxicity of variations (high and low) in vancomycin levels induced by multi-infusion with a peripheral catheter. Previous studies in our laboratory demonstrated that flow rate disturbance, which could be affected by catheter position, patient movement and fluid container height, can influence drug mass flow in patients who are treated with multiple infusions, inducing an increase or a decrease in drug concentration at the catheter egress $[10,11]$. We hypothesized that vancomycin bolus induced by drug mass flow variations simulating clinical use could induce an excess death rate of endothelial cells surrounding the catheter outlet, where the endothelial cells are subjected to a continuous flow of vancomycin with poor dilution, due to the weak 
blood flow in a peripheral vein of a patient in bed. However, our results showed that a variable concentration of vancomycin had no significant influence on toxicity compared to a fixed concentration of vancomycin with medium removal. This experiment did not induce excessive cytotoxicity beyond the cellular stress associated with frequent change of the culture medium. The limitations of this study suggest that other experiments more suitable for simulating multi-infusion need to be performed to answer this scientific question. Nevertheless, endothelial cell toxicity induced by a mechanical trauma due to multi-drug infusion, simulated in our model by medium removal and the addition of vancomycin at a constant concentration, could increase the risk of phlebitis, thus confirming our previous study [7]. This mechanical cell stress could mimic the flush induced by infusion of drugs at a high flow rate on previously damaged endothelial cells surrounding the catheter outlet. As vancomycin is frequently used in co-infusion with different drugs at different rates, it is essential to consider infusion as a whole. Curran et al. reported that the use of infusion pumps decreased the rate of phlebitis [14], and our previous study recommended using a specific access for vancomycin infusion to avoid potential drug incompatibilities. Flow rate variations induced by multi-drug infusion on the same line could be a supplementary argument. It would therefore be interesting to explore the endothelial toxicity of vancomycin administered at different rates by another method without medium removal. Testing cytotoxicity in real time by administering vancomycin at a variable concentration on cell biochips would avoid the cell stress associated with frequent medium change. On the other hand, a recent study showed that leachable materials released by infusion sets during infusion could induce local cytotoxicity [15]. Other theories remain to be explored, such as the influence of infusion set materials, in order to optimize methods of administering vancomycin by peripheral intravenous infusion (PIV).

\section{Materials and Methods}

\subsection{Cell Culture}

The drugs used, the cell culture method, and the cell vitality assessment were described in our previous study [6]. The HUVEC cell line was provided by Promocell GmbH, Heidelberg, Germany. Briefly, these cells were cultured with cell culture medium (endothelial cell growth medium enriched with endothelial cell growth SupplementMix, Promocell $\mathrm{GmbH}$, Heidelberg, Germany) for $24 \mathrm{~h}$ to obtain an $80 \%$ confluent monolayer in a 96-well plate as an in vitro model of the vascular endothelium.

\subsection{Incubation with Vancomycin}

\subsubsection{Methodology to Study Concentration-Dependent Cytotoxicity}

As shown in a previous study [6], vancomycin infusion at concentrations over $5 \mathrm{mg} / \mathrm{mL}$ induced 50\% endothelial cell death over $24 \mathrm{~h}$. We therefore only applied concentrations between 1 and $4 \mathrm{mg} / \mathrm{mL}$.

The culture medium was removed from each well of the monolayer cells, the cells were rinsed with Phosphate-Buffered Saline $1 \mathrm{X}$, then a vancomycin solution was added to the monolayer cells.

The range of vancomycin concentrations $(1-4 \mathrm{mg} / \mathrm{mL})$ was prepared with the vancomycin powder (Mylan, France) reconstituted in $\mathrm{NaC} 1(0.9 \%)$ to obtain a concentration of $500 \mathrm{mg} / 10 \mathrm{~mL}$ and diluted with cell culture medium at 50/50 (v/v).

\subsubsection{Methodology to Study Multi-Infusion-Dependent Cytotoxicity}

Flow variations during multi-infusion therapy were simulated as follows: we set a sudden decrease in drug delivery by replacing vancomycin (VAN) with $\mathrm{NaCl}(0.9 \%)$ for $30 \mathrm{~min}$ or $1 \mathrm{~h}$ every $1 \mathrm{~h} \mathrm{30}$, and a sudden increase by trebling vancomycin concentration on one occasion for $30 \mathrm{~min}$ (Table 1, VAN with concentration variations). A schematic representation of variations in vancomycin concentrations over $10 \mathrm{~h}$ for the variable concentration group is shown in Figure 2. 
Table 1. Procedure for cellular test with variations in vancomycin (VAN) concentrations. HUVECs were exposed to vancomycin at a fixed concentration $1 \times$ (corresponding to $1,1.5,2,3$, and $4 \mathrm{mg} / \mathrm{mL}$ ) with or without medium removal, or to vancomycin with a variable concentration, simulating clinical use over $10 \mathrm{~h}(\mathrm{H}) . \mathrm{NaCl}(0.9 \%)$ replaced vancomycin when VAN $=0 \mathrm{mg} / \mathrm{mL}$. For experimental conditions 2 and 3 , the cell culture medium was removed at the times specified in the table.

\begin{tabular}{|c|c|c|c|}
\hline Time & $\begin{array}{l}\text { Condition 1: Fixed } \\
\text { Concentration of } \\
\text { Vancomycin without } \\
\text { Medium Removal }\end{array}$ & $\begin{array}{l}\text { Condition 2: Fixed } \\
\text { Concentration of } \\
\text { Vancomycin with } \\
\text { Medium Removal }\end{array}$ & $\begin{array}{l}\text { Condition 3: } \\
\text { Variable } \\
\text { Concentration of } \\
\text { Vancomycin }\end{array}$ \\
\hline $\mathrm{H} 0$ to $\mathrm{H} 1$ & \multirow{15}{*}{ VAN: $1 X$} & VAN: $1 X$ & VAN: $1 X$ \\
\hline $\mathrm{H} 1$ to $\mathrm{H} 2$ & & VAN: $1 \mathrm{X}$ & $\mathrm{VAN}=0 \mathrm{mg} / \mathrm{mL}$ \\
\hline $\mathrm{H} 2$ to $\mathrm{H} 2.5$ & & VAN: $1 X$ & VAN: $1 \mathrm{X}$ \\
\hline $\mathrm{H} 2.5$ to $\mathrm{H} 3$ & & VAN: $1 \mathrm{X}$ & $\mathrm{VAN}=0 \mathrm{mg} / \mathrm{mL}$ \\
\hline $\mathrm{H} 3$ to $\mathrm{H} 4$ & & VAN: $1 X$ & VAN: $1 X$ \\
\hline $\mathrm{H} 4$ to $\mathrm{H} 5$ & & VAN: 1X & $\mathrm{VAN}=0 \mathrm{mg} / \mathrm{mL}$ \\
\hline H5 to H5.5 & & VAN: $1 X$ & VAN: $1 X$ \\
\hline $\mathrm{H} 5.5$ to $\mathrm{H} 6$ & & VAN: $1 X$ & $\mathrm{VAN}=0 \mathrm{mg} / \mathrm{mL}$ \\
\hline H6 to H6.5 & & VAN: $1 X$ & VAN: $1 X$ \\
\hline $\mathrm{H} 6.5$ to $\mathrm{H} 7$ & & VAN: 1X & VAN: 3X \\
\hline $\mathrm{H} 7$ to $\mathrm{H} 7.5$ & & VAN: $1 X$ & VAN: $1 X$ \\
\hline H7.5 to H8.5 & & VAN: $1 X$ & $\mathrm{VAN}=0 \mathrm{mg} / \mathrm{mL}$ \\
\hline $\mathrm{H} 8.5$ to $\mathrm{H} 9$ & & VAN: $1 X$ & VAN: $1 X$ \\
\hline H9 to H9.5 & & VAN: $1 X$ & $\mathrm{VAN}=0 \mathrm{mg} / \mathrm{mL}$ \\
\hline H9.5 to H10 & & VAN: $1 X$ & VAN: $1 X$ \\
\hline
\end{tabular}

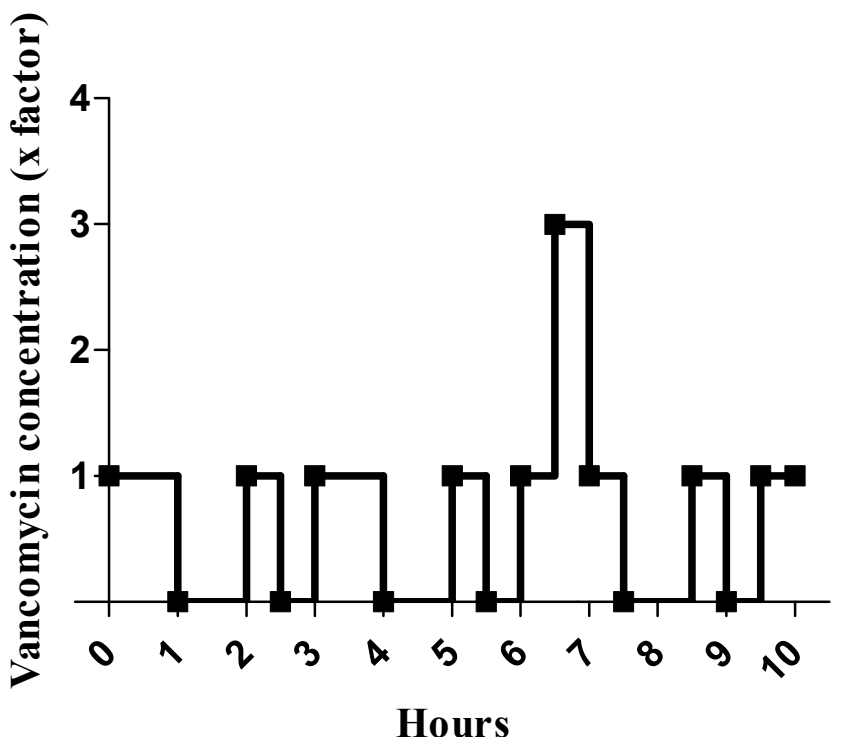

Figure 2. Schematic representation of vancomycin (VAN) concentration variations during the cellular test. Vancomycin concentration is represented by a multiple of the initial concentration, which is $1 \mathrm{mg} / \mathrm{mL}$.

To assess cell stress due to frequent medium removal from monolayer cells, we also set a control group, in which the addition of vancomycin was replaced by new vancomycin solution at the same concentration at each hourly change (Table 1, VAN at fixed concentration with medium removal). After a $24 \mathrm{~h}$ culture, the percentage of cell viability was 
compared to controls established with a fixed concentration solution of vancomycin with and without medium removal.

Excess cell death was calculated by comparing the cell death rate obtained with (1) vancomycin at a fixed concentration without medium removal and (2) vancomycin at a fixed concentration with medium removal.

\subsection{Cytotoxicity Testing}

After a $24 \mathrm{~h}$ culture with exposure to antibiotic solutions, cell reactions were evaluated by fluorometric assay with non-toxic AlamarBlue ${ }^{\circledR}$ dye (Interchim, Montluçon, France), which is equivalent to the MTT (3-(4,5-dimethylthiazol-2-yl)-2,5-diphenyltetrazolium bromide) test to determine mammalian cell toxicity [16,17]. After $24 \mathrm{~h}$ of exposure, results were expressed as the percentage of cell viability compared to a control established with $\mathrm{NaCl}$ $(0.9 \%)$ mixed with cell culture medium at 50/50 (v/v). Each test group was performed in triplicate.

\subsection{Statistical Analysis}

Non-parametric tests were used to compare percentages of HUVECs surviving with the null hypothesis that there was no difference between the experimental conditions assessed. The Kruskal-Wallis test was used to assess the toxicity of vancomycin in the three conditions. In the event of a significant $p$-value $(<0.05)$, an analysis using the Conover and Iman method was performed to detect significant differences between couples of contact time. Each of these tests was performed with XLSTAT software version 2012.2.01 (Addinsoft, Paris, France).

\section{Conclusions}

Although the endothelial toxicity of vancomycin is known to be concentration-dependent, vancomycin did not induce excessive cytotoxicity beyond the cellular stress induced by the simulated multi-infusion conditions. These results can be explained by the cell stressinduced excess mortality associated with the frequent change of the culture medium. Vancomycin-induced phlebitis could have other causes than variation in drug mass flow. To ensure that vancomycin-induced phlebitis must have other causes than variation in drug mass flow rate, further in vitro experiments should be performed to limit mechanical stress due to frequent culture medium change. If our results are confirmed, the mechanical stress related to multidrug infusion should be avoided by using a specific access for vancomycin infusion.

Author Contributions: Conceptualization, M.D., F.C. and B.D.; methodology, M.D., F.C. and B.D.; software, M.D. and F.C.; validation, M.D. and F.C.; formal analysis, M.D. and F.C.; investigation, M.D. and F.C.; resources, M.D. and F.C.; data curation, M.D. and F.C.; writing-original draft preparation, M.D. and F.C.; writing-review and editing, M.D., E.C., F.C., S.G., P.O. and B.D.; visualization, E.C.; supervision, B.D.; project administration, B.D.; funding acquisition, P.O. All authors have read and agreed to the published version of the manuscript.

Funding: This research received no external funding.

Institutional Review Board Statement: Not applicable.

Informed Consent Statement: Not applicable.

Data Availability Statement: Not applicable.

Acknowledgments: This study was funded by intramural funds from the GRITA department, ULR 7365, Pharmacy faculty, Lille University, France.

Conflicts of Interest: The authors declare no conflict of interest. 


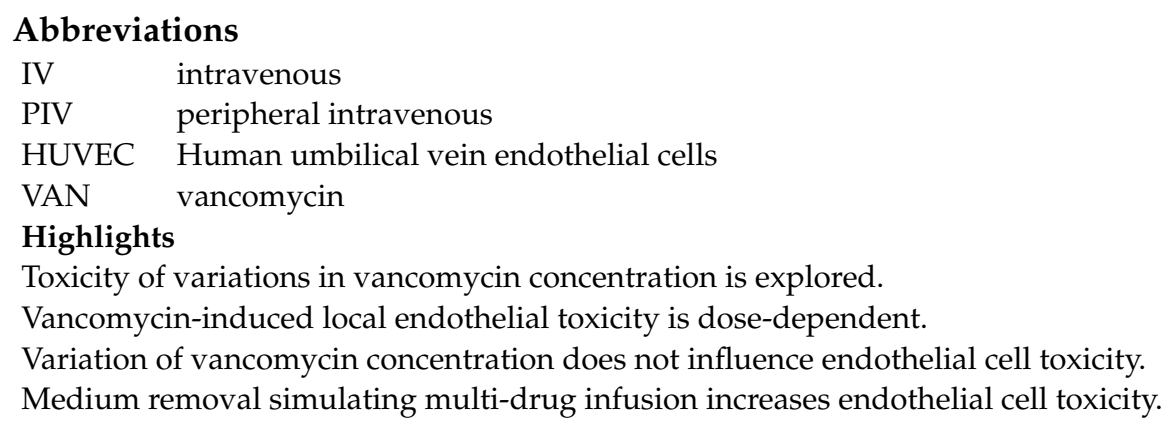

\section{References}

1. Peng, Y.; Li, C.-Y.; Yang, Z.-L.; Shi, W. Adverse reactions of vancomycin in humans: A protocol for meta-analysis. Medicine 2020 99, e22376. [CrossRef]

2. $\quad$ Bruniera, F.R.; Ferreira, F.M.; Saviolli, L.R.M.; Bacci, M.R.; Feder, D.; Pedreira, M.; Peterlini, M.A.S.; Azzalis, L.A.; Junqueira, V.B.C.; Fonseca, F.L. The use of vancomycin with its therapeutic and adverse effects: A review. Eur. Rev. Med. Pharmacol. Sci. 2015, 19, 694-700. [PubMed]

3. Agence Nationale de Sécurité du Médicament et des Produits de Santé. Résumé des Caractéristiques du Produit Vancomycine 500 mg Poudre Pour Solution Pour Perfusion. Available online: http://agence-prd.ansm.sante.fr/php/ecodex/rcp/R0187161.htm (accessed on 17 December 2021).

4. Talakoub, S.; Tork-Torabi, M.; Namnabati, M.; Allameh, Z. Vancomycin infusion methods on phlebitis prevention in children. Iran. J. Nurs. Midwifery Res. 2019, 24, 432-436. [CrossRef]

5. Robibaro, B.; Vorbach, H.; Weigel, G.; Weihs, A.; Hlousek, M.; Presterl, E.; Georgopoulos, A.; Griesmacher, A.; Graninger, W. Endothelial cell compatibility of glycopeptide antibiotics for intravenous use. J. Antimicrob. Chemother. 1998, 41, 297-300. [CrossRef]

6. Drouet, M.; Chai, F.; Barthelemy, C.; Lebuffe, G.; Debaene, B.; Décaudin, B.; Odou, P. Influence of Vancomycin Infusion Methods on Endothelial Cell Toxicity. Antimicrob. Agents Chemother. 2014, 59, 930-934. [CrossRef]

7. Drouet, M.; Chai, F.; Barthelemy, C.; Lebuffe, G.; Debaene, B.; Décaudin, B.; Odou, P. Endothelial Cell Toxicity of Vancomycin Infusion Combined with Other Antibiotics. Antimicrob. Agents Chemother. 2015, 59, 4901-4906. [CrossRef]

8. Lovich, M.A.; Doles, J.; Peterfreund, R.A. The Impact of Carrier Flow Rate and Infusion Set Dead-Volume on the Dynamics of Intravenous Drug Delivery. Anesth. Analg. 2005, 100, 1048-1055. [CrossRef] [PubMed]

9. Timmerman, A.M.; Snijder, R.; Lucas, P.; Lagerweij, M.C.; Radermacher, J.H.; Konings, M.K. How physical infusion system parameters cause clinically relevant dose deviations after setpoint changes. Biomed. Tech. Eng. 2015, 60, 365-376. [CrossRef] [PubMed]

10. Décaudin, B.; Dewulf, S.; Lannoy, D.; Simon, N.; Secq, A.; Barthélémy, C.; Debaene, B.; Odou, P. Impact of Multiaccess Infusion Devices on In Vitro Drug Delivery During Multi-Infusion Therapy. Anesth. Analg. 2009, 109, 1147-1155. [CrossRef] [PubMed]

11. Lannoy, D.; Decaudin, B.; Simon, N.; Barthelemy, C.; Debaene, B.; Odou, P. The Impact on Drug Mass Flow Rate of Interrupting and Resuming Carrier Fluid Flow: An in vitro study on a very low dead-space volume infusion set. Anesth. Analg. 2012, 114, 328-332. [CrossRef] [PubMed]

12. Millrose, M.; Kruse, M.; Flick, B.; Stahlmann, R. Effects of macrolides on proinflammatory epitops on endothelial cells in vitro. Arch. Toxicol. 2008, 83, 469-476. [CrossRef] [PubMed]

13. Vorbach, H.; Weigel, G.; RobibaroO, B.; Armbruster, C.; Schaumann, R.; Hlousek, M.; Reiter, M.; Griesmacher, A.; Georgopoulos, A. Endothelial cell compatibility of clarithromycin for intravenous use. Clin. Biochem. 1998, 31, 653-656. [CrossRef]

14. Curran, E.; Coia, J.; Gilmour, H.; McNamee, S.; Hood, J. Multi-centre research surveillance project to reduce infections/phlebitis associated with peripheral vascular catheters. J. Hosp. Infect. 2000, 46, 194-202. [CrossRef] [PubMed]

15. Kozlovskaya, L.; Stepensky, D. Mechanisms of cell death induced by infusion sets leachables in in vitro experimental settings. Int. J. Pharm. 2015, 478, 693-701. [CrossRef] [PubMed]

16. Hamid, R.; Rotshteyn, Y.; Rabadi, L.; Parikh, R.; Bullock, P. Comparison of alamar blue and MTT assays for high through-put screening. Toxicol. Vitr. 2004, 18, 703-710. [CrossRef] [PubMed]

17. Rampersad, S.N. Multiple Applications of Alamar Blue as an Indicator of Metabolic Function and Cellular Health in Cell Viability Bioassays. Sensors 2012, 12, 12347-12360. [CrossRef] [PubMed] 